\title{
sustainability
}

ISSN 2071-1050

www.mdpi.com/journal/sustainability

Article

\section{A Dual Function Energy Store}

\section{Ron Tolmie ${ }^{1, *}$ and Marc A. Rosen ${ }^{2}$}

1 Sustainability-Journal.ca, 217 Petrie Lane, Kanata, ON K2K 1Z5, Canada

2 Faculty of Engineering and Applied Science, University of Ontario Institute of Technology, 2000 Simcoe Street North, Oshawa, ON L1H 7K4, Canada; E-Mail: marc.rosen@uoit.ca

* Author to whom correspondence should be addressed; E-Mail: tolmie129@rogers.com; Tel.: +1-613-271-9543.

External Editors: Ibrahim Dincer and Francesco Asdrubali

Received: 17 March 2014; in revised form: 11 August 2014 / Accepted: 10 November 2014 /

Published: 20 November 2014

\begin{abstract}
Heat can be collected from local energy sources and concentrated into a relatively small volume, and at a useful working temperature, by using a heat pump as the concentrator. That heat can be stored and utilized at a later date for applications like space heating. The process is doing two things at the same time: storing heat and shifting the power demand. The concentration step can be done at night when there is normally a surplus of power and its timing can be directly controlled by the power grid operator to ensure that the power consumption occurs only when adequate power is available. The sources of heat can be the summer air, the heat extracted from buildings by their cooling systems, natural heat from the ground or solar heat, all of which are free, abundant and readily accessible. Such systems can meet the thermal needs of buildings while at the same time stabilizing the grid power demand, thus reducing the need for using fossil-fuelled peaking power generators. The heat pump maintains the temperature of the periphery at the ambient ground temperature so very little energy is lost during storage.
\end{abstract}

Keywords: exergy; energy storage; ground energy; solar; space heating; air conditioning; domestic hot water; demand reduction 


\section{Introduction}

Energy can be stored in the ground in the form of heat and the systems can be designed so that the storage temperatures are suitable for meeting the thermal needs of the buildings they serve, so they require little or no additional energy at the time of energy extraction. The timing of the thermal injection is not critical so such systems can use electrically driven heat pumps to store the energy at times of surplus generation capacity and subsequently withdraw the heat at those times when the energy demand is high. The system is therefore accomplishing two tasks at the same time: storing the heat for when it is needed and shifting the electricity consumption from high to low demand periods. The paper discusses the design considerations and provides an assessment of what might be achieved if such systems were widely employed in Ontario, Canada.

\section{Concept}

Buildings use energy in two forms: electrical and thermal, and the rate of consumption of both varies with the seasons and the time of day [1]. The traditional way of handling those variations has been to design the energy supply systems so that they are capable of meeting the peak demands. An alternative approach is to use energy storage to flatten the temporal fluctuations in demand. That can be concurrently accomplished for both forms of energy by employing what is called an exergy store [2]. An exergy store collects heat from various sources around the buildings and stores that heat in the ground. At those times when the demand for grid power is low a heat pump is employed to concentrate the heat into a smaller volume in the ground and at a higher temperature, thus boosting its exergy. Such systems can be designed so that the higher temperature will be suitable for directly heating the buildings. The consequence is that very little electric power is consumed during the periods of peak energy demand and is instead consumed only when ample power is available (primarily at night), thus in effect storing the electricity.

The concept can be extended to store cold as well as heat and to store heat at the temperature that is needed for domestic hot water (DHW) so that nearly all of the thermal needs of the buildings can be met using local thermal energy sources. In Canada those thermal needs for buildings are generally greater than the electricity needs (for example, Ontario's residential buildings use $88 \%$ of their energy in thermal form and only $12 \%$ in electrical form $[3,4]$ ). Since a heat pump uses a small amount of electricity to move a larger amount of thermal energy this imbalance opens up the potential to build systems that shift power load to the nighttime, which is useful for the power grid, while concentrating a much larger amount of thermal energy and raising its temperature, storing that energy for later use for heating buildings. A single system is thus accomplishing two functions at the same time.

The storage system (Figure 1) has two rings of boreholes containing ground heat exchangers like those used for ground source heat pump systems [5] (GSHP's). The boreholes will vary in depth, typically from 10 to $500 \mathrm{~m}$, to match the storage requirement. The spacing between the two rings is determined by the velocity of the heat flow, the objective being to retain heat that was injected in the summer for use six months later during the winter.

During the daytime in the summer heat is extracted from a heat source (such as the air), transferred into a heat exchange fluid, and then transferred into the ground around the outer boreholes. At night the heat pump extracts this heat via the ground heat exchangers, raises its temperature, and transfers it into a smaller volume near the center of the store. If the amount of heat that is extracted at night equals the 
amount that had been injected during the day then the peripheral temperature will remain at the ambient ground temperature so none of the stored heat will be lost via the periphery. The purpose of the heat pump is not to add energy but rather to concentrate the heat into a smaller, hotter region, thus raising its exergy. The objective is to store the heat at a high enough temperature to enable its direct use for space heating so that no power is required during the heat recovery stage (which normally coincides with periods of high power demand). The power demand thus occurs at night when the grid power demand is low. The system thus serves the dual purposes of storing heat for space heating and of shifting the power demand from high grid demand periods to low demand periods. From the point of view of the grid operator the effect on the power demand is the same as what would have been achieved if a battery had been used to store power.

Figure 1. The basic principle of the storage system.

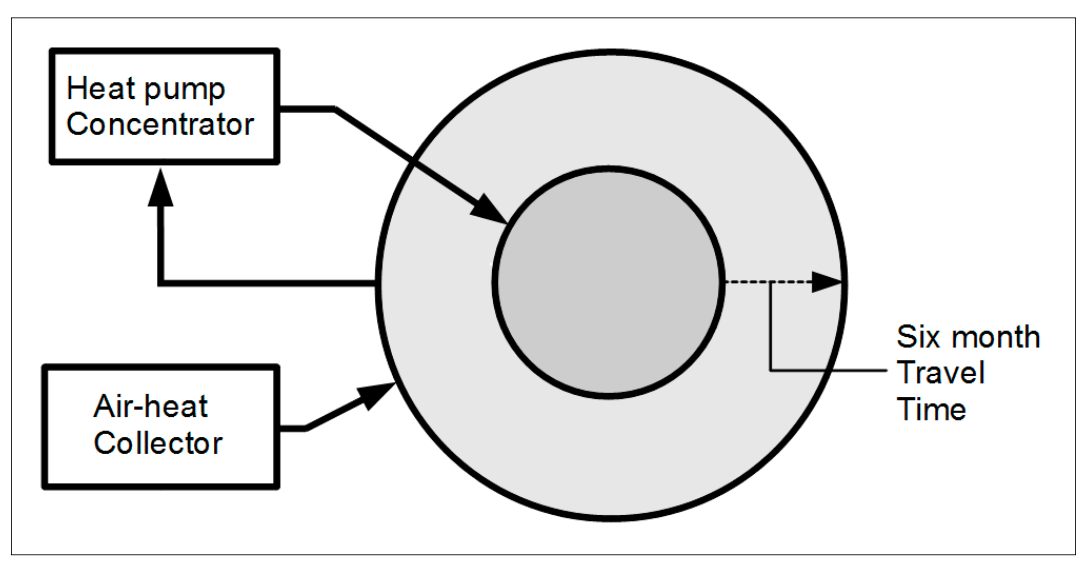

Once the heat has been transferred into the core some of it will start flowing outwards again. However, the spacing between the inner and outer boreholes has been selected so that it takes six months for the heat to reach the outer boreholes. The heat has thus been trapped in the store for that length of time. When the out-flowing heat reaches the outer ring the heat pump can once again return it to the center but this time the added heat will not flow outwards because by then the general direction of heat flow is always towards the central boreholes from which heat is being extracted to heat the buildings. The returned energy and exergy are thus trapped close to the inner boreholes and can be recovered at a later date. When the energy is recovered that part of the stored energy can be extracted at a relatively high rate because that heat has been trapped close to the boreholes. Such systems are consequently capable of delivering thermal power at a higher rate than GSHP's. This effectively provides a very efficient method for "storing" the electricity. The second pass through the heat pump increases the electricity consumption so it reduces the seasonal coefficient of performance [6] (COP) but creating the ability to "store" electricity on a daily basis is more important. The ability to extract heat at a high rate has another benefit: it reduces the length of the ground heat exchangers. The cost of these ground heat exchangers and of drilling the boreholes represents the dominant system cost. In such systems the cost of the energy itself is zero so it is the capital cost and the cost of the electricity that determine the cost of the energy they deliver. The nighttime cost of electricity is much lower than its daytime cost so both of the basic costs are reduced.

One upshot of the concept is that no energy is lost through the periphery, which remains at or slightly below the ambient ground temperature at all times. Some energy is lost through the top and bottom of 
the store but it is easy to insulate tubes at the top and to shorten the central boreholes to shape the temperature profile at the bottom to minimize the loss in that region. Relatively little heat flows in those directions anyway because their areas are so small compared to the area of the store's periphery. The end result is that this type of store loses very little of the energy that is injected into it.

The spacing between the outer boreholes must be close enough to prevent heat from flowing out between them. During the daily cycle the temperature of the ground close to the boreholes will rise and fall but the injection can be adjusted so that the average ground temperature (for Ontario) is 8 degrees (about 2 degrees less than the ambient ground temperature) and that temperature will propagate out, filling the space between the boreholes before any heat from the core reaches the periphery, after which the out-flowing heat will be redirected to the outer boreholes and will be re-collected. In large systems meeting this objective may require more than the 8 boreholes shown in the diagram but a large system would require more boreholes anyway because it requires more heat exchanger length to handle the greater energy transfer rate.

In practice space heating systems need to be able to handle very high peak loads on cold winter nights, and the buildings also need hot water. Both of those functions can be provided by injecting solar heat into the core of the facility as shown in Figure 2. During the summer the solar collectors will deliver more heat than is needed for the hot water. This excess heat can be transferred to the storage zone used for storing space heat, partly via heat conduction in the ground and partly by transferring some of it directly to the middle ring of heat exchangers (indicated by the dashed line in the diagram). This solar input peaks several weeks before the temperature of the air peaks so the solar heat should be injected into the four holes that are slightly outside of the middle ring to flatten the temperature profile in that region. A parallel plate heat exchanger should be used for transferring the heat from the solar collectors so that the solar and heating flow loops can operate independently.

Figure 2. Diagram of a 20 borehole exergy storage system (including the solar component).

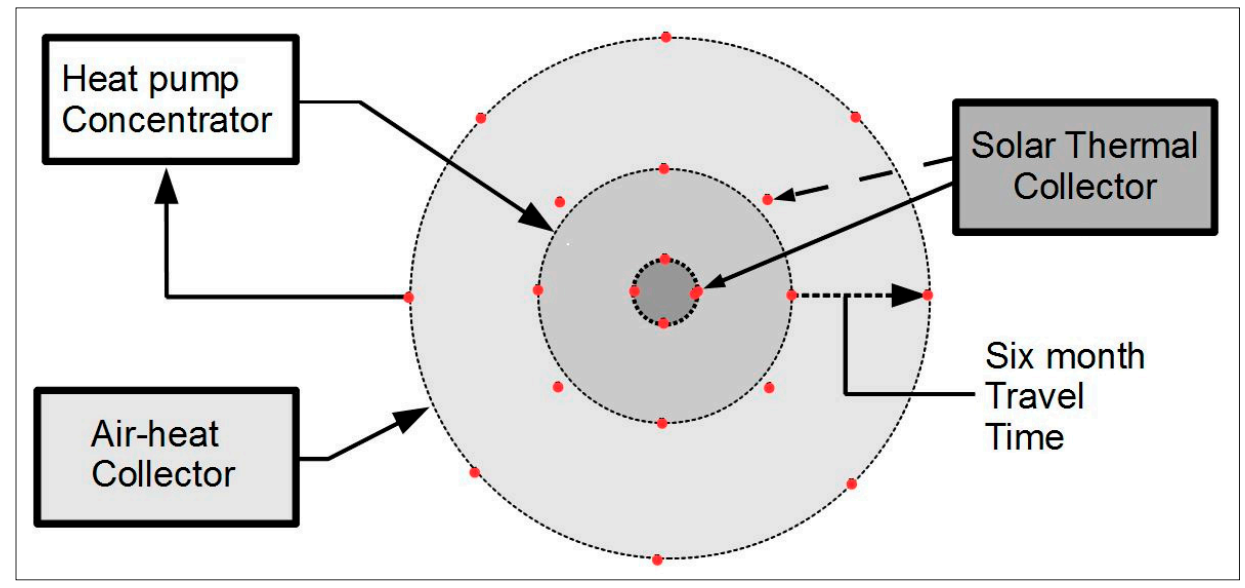

A solar thermal collector feeding its output to a small group of boreholes would not normally attain the required 60 degree ground temperature because the heat in the ground would flow away too quickly, but by surrounding that borehole with a middle ring that will heat the ground to an intermediate temperature (40 to 50 degrees) the desired core temperature can be achieved. Systems like the Drake Landing [7] installation in Alberta have demonstrated that ground stores can be operated successfully at 
such temperatures. The link to the middle ring also provides a means of limiting the upper temperature of the solar loop and of regulating the temperature of the central store.

This configuration provides long term storage of the solar heat and ensures that nearly all of the heat supplied by the solar collectors is efficiently utilized either for DHW or for space heating. The core is nominally 20 degrees hotter than the space-heat zone so it is capable of delivering heat at a very high rate in support of the space heating loop when that extra heat is needed on very cold nights. Such a high drain might temporarily drop the output temperature of the hot water loop but the hot water tanks in the buildings will make up for such temporary drops (these tanks are ordinary hot water tanks with electric heaters to ensure that they always maintain the required DHW temperature).

By early winter most of the heat that has been injected into the store will reside in the region between the middle and outer rings (Figure 3). The challenge is to collect as much as possible of that heat by the end of the heating season. As the winter progresses much of the injected heat will return to the middle rings and will be extracted to heat the buildings. The balance will flow outwards and will be returned (and trapped) by the heat pump so it too will be used for space heating. In the spring the output from the middle rings can be allowed to drop below 40 degrees, partly because less heating will be needed by then and partly because the central solar store provides a substantial backup capacity. There is little chance that the store will run out of heat in the spring because the heat pump can also extract natural ground heat which provides a large energy reserve.

Figure 3. The left half of the predicted temperature profile across the store on a sunny winter day. The center peak is temporary because heat was injected earlier in the day.

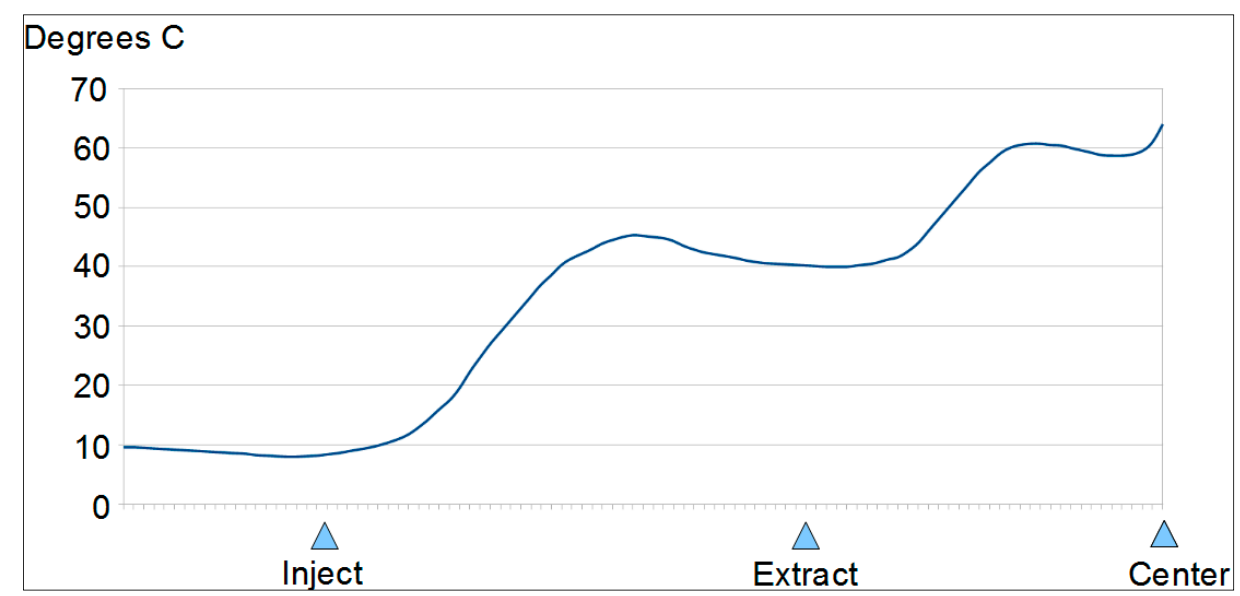

The diameter of the store will typically be in the range of 20 to $30 \mathrm{~m}$ and the depth can vary between 10 and $500 \mathrm{~m}$, depending on the required storage capacity. For residential applications a convenient deployment would be to use one store per city block. Where the store is to be retrofitted to an existing set of buildings there will not always be sufficient space available to permit vertically drilled boreholes, in which case a steerable drill can be used to minimize the access area for the drilling. The inner tubes should use insulating sleeves for the top several metres. Such insulation is not needed for the outer tubes because they operate at nearly the ambient ground temperature.

The design of the exergy storage system is derived from that of a "testbed" system that has been in use for five years in Kingston, Ontario, shown in Figure 4. That system [8] delivers $25 \mathrm{~kW}$ of heat from only $120 \mathrm{~m}$ of boreholes, for a ratio of 208 watts per metre, which is much higher than the rate of 
extraction that is normally achieved with ground source heat pump systems. Achieving a high extraction per metre is important because the largest expense in building ground based systems is the cost of drilling the boreholes and fitting their heat exchange piping. The "testbed" employs heat exchangers with enhanced efficiency and a buffer that helps to flatten the diurnal temperature swings but the more significant feature is the use of heat trapping in the volume of ground around the ground heat exchangers. During the winter any heat that is injected into that zone is trapped there because the surrounding temperature gradient drops in temperature as you approach the boreholes. Heat can only travel from hot to cold regions so it cannot move away from the boreholes. Moreover, because it is contained so close to the pipes it can be extracted very quickly, leading to the high $208 \mathrm{w} / \mathrm{m}$ extraction rate and in turn to a comparatively low system cost.

Figure 4. The "testbed" system. The store is buried under the lawn (six boreholes, $20 \mathrm{~m}$ deep). The air-heat collector is behind the bushes on the right. The heat pump is in the basement. A pair of solar collectors is mounted on the roof (lower right).

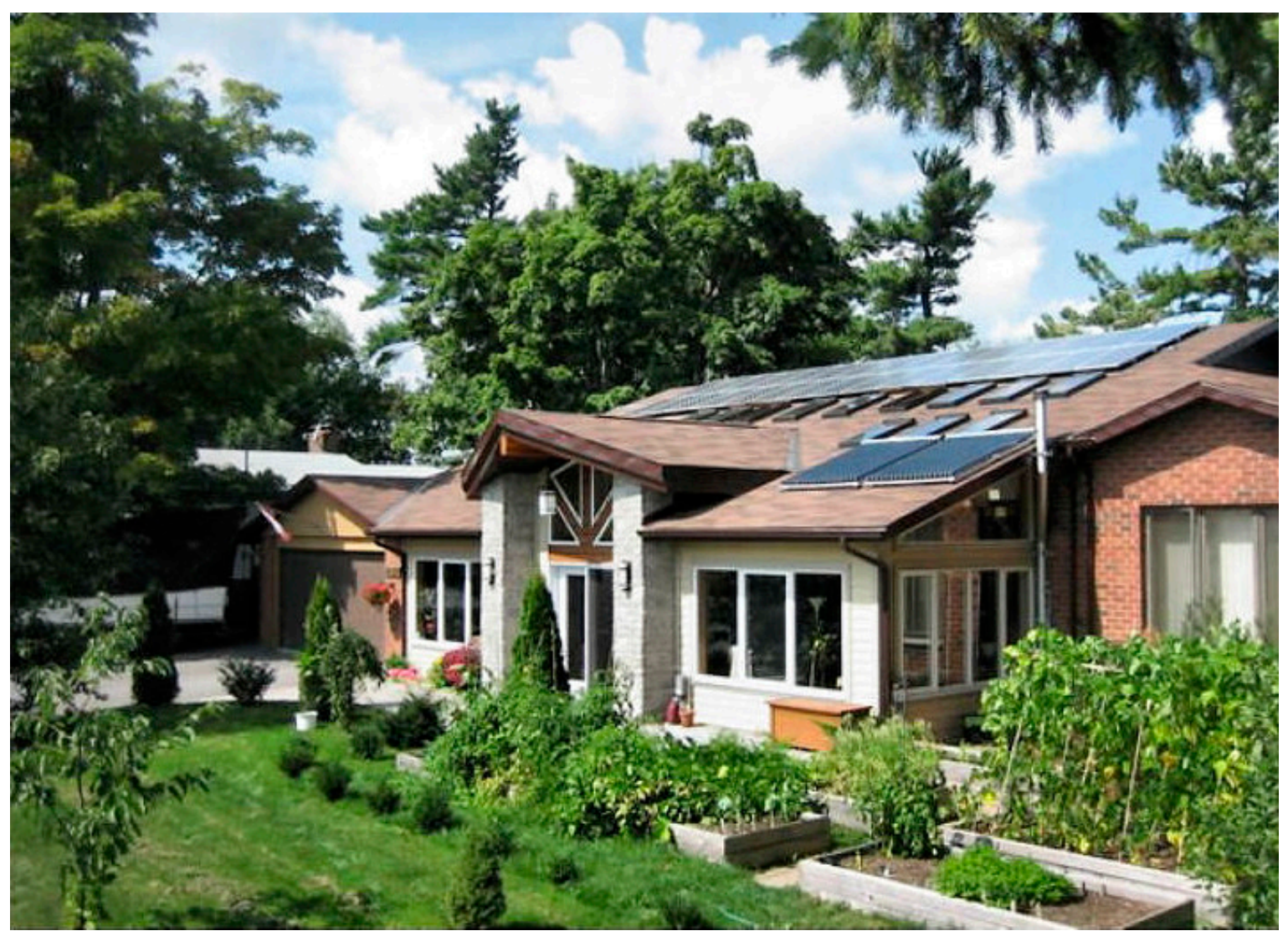

The "testbed" system (diagram: Figure 5) uses heat extracted from the air with the $50 \mathrm{~kW}$ air-heat exchanger shown in Figure 6, injecting that heat into the central region of the store. However, in that type of system the central zone progressively heats up so that by mid-summer the rate of heat injection is greatly reduced, limiting the annual storage capacity. That problem is eliminated in exergy storage systems because the air-heat collectors inject the heat into a zone that is held at a constant 8 degrees $\mathrm{C}$.

Although the "testbed" has only six boreholes it has established the feasibility of utilizing the four local energy sources, of being able to store the heat in the ground with low losses, and of being able to achieve the very high heat exchange rates needed to minimize the required borehole length. 
Figure 5. Diagram of the earlier "atmospheric energy" type of system.

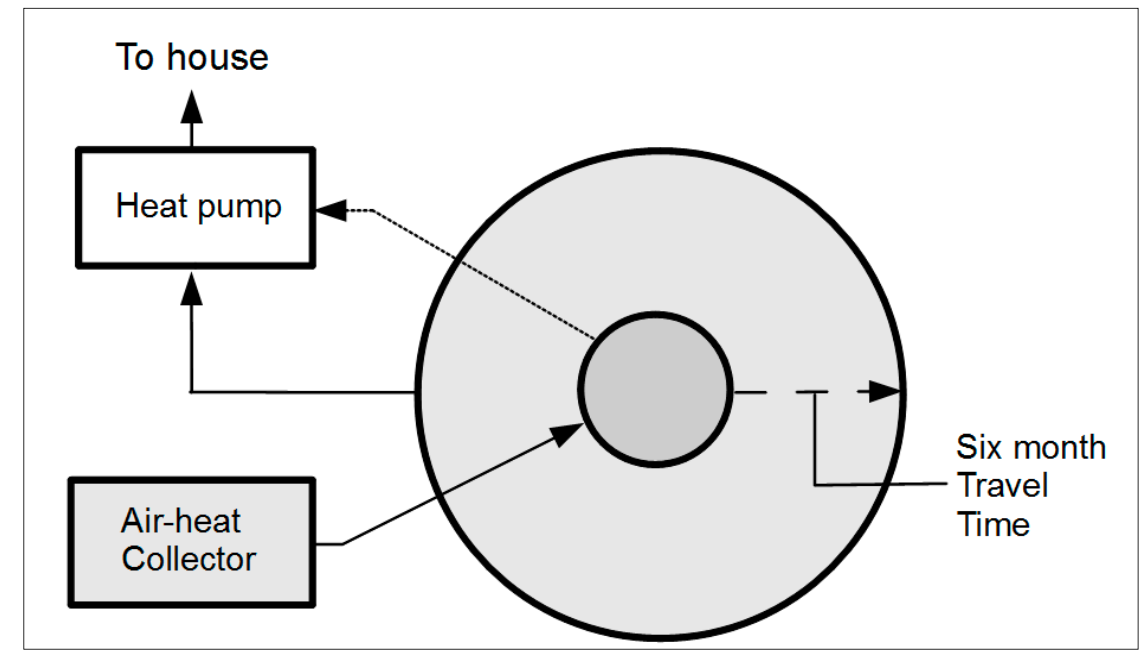

Figure 6. Photo of the $50 \mathrm{~kW}$ air-heat collector.

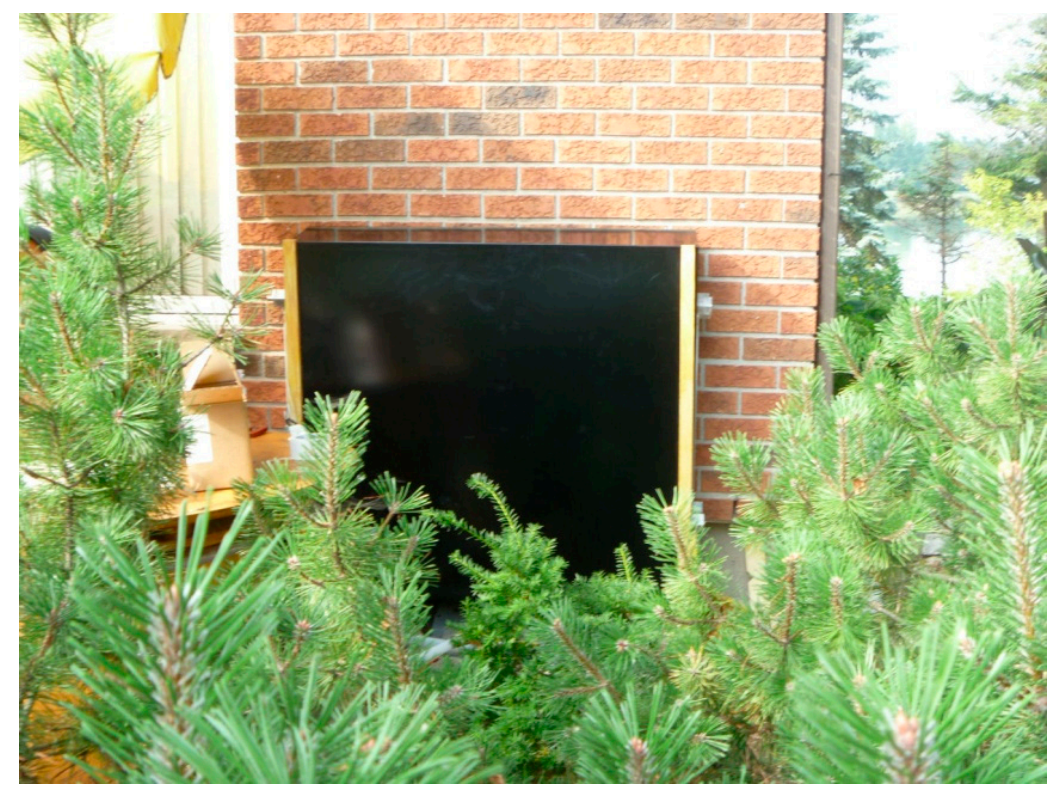

\section{The Four Local Thermal Energy Sources}

The designer of an exergy store can choose from four sources of heat (Figure 7):

(a) Solar heat. A heat pump that is using heat that is extracted from the ground at 8 degrees cannot readily raise the central temperature to the 60 degrees $\mathrm{C}$ that is needed for DHW. However, conventional solar thermal collectors are suitable for that task, and they operate very efficiently in this application because their excess output in the summer contributes to the heat that is stored for space heating. Moreover, the hot solar-heated core provides a large reserve of heat that can be used to boost the space heating capacity on very cold winter nights.

(b) Heat from the air conditioning system. This needs a heat sink that operates at 4 to 8 degrees. Normally the loop for the outer boreholes operates at 8 degrees but when hot weather is expected the control system can be used to temporarily drop the loop temperature to 4 degrees. Since the change is only temporary it will not significantly affect the peripheral temperature. 
(c) Heat from the summer air. This is a virtually unlimited source of energy that is easy to exploit in this kind of system because the outer ring, into which the heat from the air-source heat exchangers is to be deposited, is always at a low temperature.

(d) Natural heat from the ground. This provides insurance against situations where the amount of injected heat is exhausted for reasons that were unforeseen. There are some applications in which natural ground heat would be useful as a major energy source.

Figure 7. The input/output parameters.

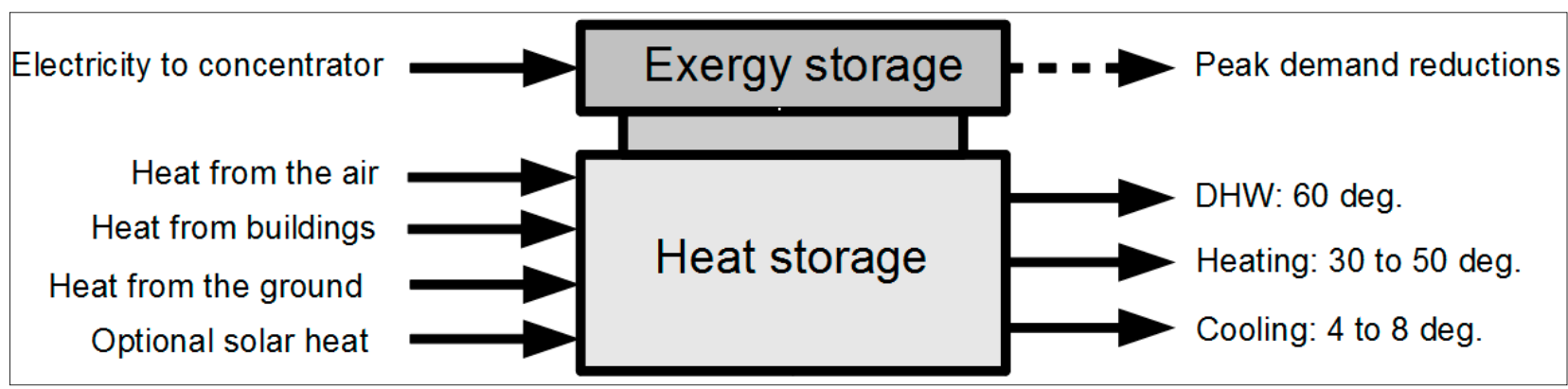

In some cases the solar collectors might conceptually be replaced by using a second heat pump to transfer heat from the middle zone of the store to the core. That boosts the time-shift capacity for power but to compensate for the loss of the solar input extra heat will be needed from the other local energy sources. This extra heat can be drawn either from the ground or from the air, the choice being dependent on local circumstances. The use of a second heat pump is particularly attractive in situations where there might be a substantial surplus of power at night, for example in an area with many wind turbines.

This ability to utilize heat from a variety of local sources makes it possible to adapt exergy stores for a wide variety of situations and also to match the electricity supply and demand for fixed output power sources (nuclear and hydro) and as well as for fluctuating sources like wind turbines.

In Ontario there is frequently an excess of electricity generation capacity during the night, when the power demand is low, and this excess generation capacity is currently being wasted, either by throttling back the generators or by exporting the excess electricity at a low price. Adding storage to the energy supply system makes it possible to utilize that wasted generation capacity.

\section{Reducing Power Demand Fluctuations}

The power demand cycle in Ontario goes through two seasonal power demand peaks, one in the summer that is caused by the power consumption of air conditioning equipment and one in the winter that is caused by the use of electricity for heating. Both demand peaks could be reduced and eventually almost eliminated by using thermal stores to meet the heating and cooling needs. In addition there is another wide swing in power consumption that occurs on a daily basis and is caused by the normal daytime activities in homes, offices and factories. By shifting a large part of the power load to the nighttime period that daily demand swing can also be flattened.

Flattening the demand swings does not reduce the amount of energy that we use on an annual basis, but it does have four important consequences: 
(a) The generation system does not need to handle large peak loads and it does not need to maintain a large excess in capacity in order to handle unanticipated demands. At the present time the available generation capacity in Ontario is commonly more than 10,000 MW greater than the actual rate of consumption. Reducing the need to maintain a large generation capacity in order to cope with the possible peak demands would reduce the capital cost of the generation facilities.

(b) The productivity of the nuclear, hydro and wind stations could be improved because their potential nighttime output would be profitably employed.

(c) Stabilizing the daily and seasonal demands would stabilize power prices, eliminating the substantial price fluctuations that often occur at the present time.

(d) Reducing the demand fluctuations and employing local storage reduces the cost and complexity of the power distribution grid.

\section{Design Considerations}

\subsection{Space Heating}

Space heat distribution systems that employ heat pumps generally work at lower temperatures than conventional ("boiler") systems because the heat pumps are not capable of operating efficiently if they are required to work with large temperature differences between the heat source and the heat sink. Distribution systems that operate at 40 degrees $C$ appear to be a reasonable compromise, using hydronic distribution loops to feed the heat to regional air handlers that provide the local heat distribution. The challenge is to maintain the space heating loop at 40 degrees or more throughout most of the heating season, although it could be allowed to drop below that value at the end of the season because of the lower heating demand.

During the heating season, heat flows from the hot central core to the middle ring. Heat will also flow from the annulus between the middle and outer rings. By the end of summer enough heat must have been injected into this annulus to raise its central temperature well above 40 degrees but as the heating season progresses that temperature will fall as the heat flows in both directions. During this period the heat pump concentrator will return the heat that has reached the peripheral ring. These three sources need to provide enough heat to keep the system within its intended operating range. During the winter there will be periods of very cold weather and during those periods extra heat can be drawn from the hot core, which has a high storage capacity and can deliver heat at a very high rate when required. Since we have no control over the heat delivery rate of the other three sources the heat from the core also provides a means of providing temperature control. It is not essential to always maintain the core temperature at 60 degrees because the hot water tanks would safely take care of the water temperature until the solar thermal collectors can restore equilibrium.

\section{2. $\mathrm{DHW}$}

Solar thermal collectors are about six times more energy efficient than solar PV collectors so a solar thermal array on a house will be much smaller than a typical $10 \mathrm{~kW}$ solar PV array even though it is delivering more energy. Moreover the heat is being stored so the availability of hot water is stable, with the caveat that an extremely cold night could cause a temporary core temperature drop because of the redirection of heat to the space heating loop. The sizing of the solar array is determined by the demand 
for water heating during the winter. If the collector is capable of meeting that demand then it will be delivering a considerable excess of heat in the summer and that extra heat flows out to (or is deliberately fed to) the space heat storage zone. The diameter of the central solar heat storage column should be chosen so that heat just reaches the space-heat ring at the beginning of the heating season, when that heat will be needed.

\subsection{Cooling}

Very large buildings need more cooling (on an annual basis) than heating, even in a cold country like Canada. For such buildings a second exergy store can be installed with its heat pump working in the opposite direction. An air-heat exchanger is used to chill the periphery in the winter and the heat pump is used at night to bring the peripheral temperature back to the ambient ground temperature value, which chills the core. In cases that require extreme peak cooling part of the demand can be met by freezing water at night and using the extra stored cold for cooling during the day, a practice that is well established and that provides a counterpart to the hot core in the heat stores previously described. Normally buildings that use "cold" stores will also require regular "hot" stores as well in order to provide DHW, and for space heating during the coldest part of the winter.

In Canada most buildings require an annual net input of heat, especially for houses, so in general the stores should be primarily designed to store heat rather than cold. For most of the year the peripheral temperature of the store (typically 8 degrees) will be sufficient to provide adequate cooling but that will not be true on the hottest summer days. The proposed solution is to take advantage of the reasonably accurate predictions of future regional temperatures. The air-heat injection would be cut back in anticipation of a coming hot spell so that the heat pump will pre-cool the ground close to the outer boreholes, chilling the nearby ground to 4 degrees or lower, with the heat deficit being adjusted to match the expected future cooling need. When the hot weather arrives the heat deficit will be erased and the system will return to normal. Since such events are transient the ground temperature in the zones between the boreholes will be only slightly affected so there is no significant change in the peripheral heat balance.

Some buildings fall into an intermediate category where the winter heating and summer cooling require about the same amount of energy. In that case the heat can simply be shuttled back and forth between the buildings and the ground. Small imbalances can be handled by using natural ground heat, accomplished by adjusting the temperature of the outer ring by controlling the operation of the heat pump concentrator.

\section{Scope for Applications}

The potential for shifting power demand from power-deficient periods to power-surplus periods can be estimated from the statistics for energy use. For example, Ontario uses $110 \mathrm{PJ} / \mathrm{year}$ of electricity for thermal applications [9-14] (Table 1). Of that roughly $85 \mathrm{PJ} /$ year will be consumed during the power-deficient part of the day so that represents the amount of electrical energy that could be time-shifted. If you add the energy supplied by natural gas the total energy consumption for the thermal needs is $657 \mathrm{PJ} /$ year (Table 2). 
Table 1. The electricity consumption in Ontario in 2011 for thermal applications in the Residential and Commercial/Institutional Sectors.

\begin{tabular}{lc}
\hline \multicolumn{1}{c}{ Application and Building Type } & PJ/Year \\
\hline Electricity used for heating in residential sector & 36.4 \\
Electricity used for heating in commercial/institutional sector & 14.5 \\
Electricity used for cooling in residential sector & 16.1 \\
Electricity used for cooling in commercial/institutional sector & 31.9 \\
Electricity used for water heating in residential sector & 9 \\
Electricity used for water heating in commercial/institutional & 2.3 \\
\hline Total electricity used for thermal applications in 2011 & $\mathbf{1 1 0 . 2}$ \\
\hline
\end{tabular}

Note: The total electricity consumption for all applications was $326.6 \mathrm{PJ} /$ year.

Table 2. The total energy consumption (including natural gas) in 2011 for the building sectors.

\begin{tabular}{lc}
\hline \multicolumn{1}{c}{ Application and Building Type } & PJ/Year \\
\hline Total energy used for heating in residential sector & 339.6 \\
Total energy used for heating in commercial/institutional sector & 119 \\
Total energy used for cooling in residential sector & 16.1 \\
Total energy used for cooling in commercial/institutional sector & 33.9 \\
Total energy used for water heating in residential sector & 110.2 \\
Total energy used for water heating in commercial/institutional sector & 38.3 \\
\hline Total energy used for thermal applications in 2011 & $\mathbf{6 5 7 . 1}$ \\
\hline
\end{tabular}

In Ontario about $72 \mathrm{PJ} /$ year of extra generation capacity (Table 3 ) could be utilized if storage is employed to make use of the nighttime surplus generation capacity. Adding that to the $85 \mathrm{PJ} / \mathrm{year}$ of time-shifted power brings the total to $157 \mathrm{PJ} /$ year of electric energy that would be available at night to drive the heat-pump concentrators.

Table 3. Extra electricity that could be available if surplus energy is stored.

\begin{tabular}{lc}
\hline \multicolumn{1}{c}{ Potential Source of Extra Electricity Generation } & PJ/Year \\
\hline Surplus baseload hydro (OPG data) & 4 \\
Surplus baseload hydro from other hydro sites (projected) & 2.7 \\
Surplus power dumped via exports & 65.6 \\
Surplus wind power & not available \\
Unused nuclear capacity ${ }^{1}$ & not available ${ }^{1}$ \\
\hline Total & $\mathbf{7 2 . 3}$ \\
Note: ${ }^{1}$ Ontario's nuclear generation capacity is 12,947 MW (IESO data) but during periods of low demand the \\
generation falls to the 8000's, and on a daily basis the nighttime generation is usually less than the daytime \\
generation, indicating that the nuclear stations are being throttled back. This is likely to be the largest factor \\
but the data is not currently available.
\end{tabular}

The total energy consumption for thermal applications in the residential and commercial/institutional buildings sector is $657 \mathrm{PJ} /$ year. Ontario's consumption of energy for DHW is $149 \mathrm{PJ} /$ year [12,15] but about twice as much heat will be needed from the solar collectors to make up for the solar heat that is used for space heating so the balance of heat that should come from the heat pump concentrators amounts to about $359 \mathrm{PJ} /$ year. 
Given a net demand of $359 \mathrm{PJ} /$ year and an available extra electricity supply of $157 \mathrm{PJ} / \mathrm{year}$ the required seasonal COP for the heat pumps (for Ontario) would be only 2.3, which should be a readily achievable objective. If the COP were to exceed that value then there would be a surplus of electricity that would be available for other applications. That extra electricity would be in addition to the $657 \mathrm{PJ} /$ year of thermal energy being delivered to buildings from presently underutilized local energy sources.

\section{Conclusions}

The concept opens up the potential for reducing both the capital cost and the operating costs for energy in both electrical and thermal forms, for reducing the need for fossil-fuelled peaking plants, for minimizing the GHG production attributable to the buildings sector, for achieving higher efficiencies with our existing power generators, for making better use of intermittent power sources like wind turbines, and for building permanently sustainable clean, reliable, unobtrusive energy systems.

\section{Acknowledgments}

The construction of the "testbed" system in Kingston, Ontario was managed by Volker Thomsen, who made many useful contributions to the design. Building the prototype required a great deal of hard work and a strong dedication to the objectives. The performance of the heat store was monitored using a multichannel data logger that was programmed by Dave Wilson, who handled the data reduction.

\section{Author Contributions}

Ron Tolmie collected the data, prepared the illustrations and wrote the draft text. Marc A. Rosen contributed the concept of independently considering energy and exergy storage and revised the text for clarity.

\section{Conflicts of Interest}

The authors declare no conflict of interest.

\section{References and Notes}

1. IESO. Available online: http://www.ieso.ca (accessed on 21 July 2014).

2. Tolmie, R.; Rosen, M.A. Exergy Storage in the Ground, 3rd World Sustainability Forum. Available online: http://www.sciforum.net/conference/wsf3 (accessed on 21 July 2014).

3. Data of Residential Sector-Ontario (Res: Table 1). Available online: http://oee.nrcan.gc.ca/ corporate/statistics/neud/dpa/showTable.cfm?type $=\mathrm{CP} \&$ sector $=$ res\&juris $=$ on $\& \mathrm{rn}=1 \& \mathrm{page}=4 \& \mathrm{CF}$ $\mathrm{ID}=34745232 \& \mathrm{CFTOKEN}=2 \mathrm{e} 44 \mathrm{cf1} 1767 \mathrm{dc} 1118$-AD9CE054-ABBA-9D79-87EF863FD6CD9FBF (accessed on 14 November 2014).

4. Data of Commercial/Institutional Sector-Ontario (Com/Inst: Table 1). Available online: http:/oee.nrcan.gc.ca/corporate/statistics/neud/dpa/showTable.cfm?type=CP\&sector=com\&juris $=$ on\&rn=1\&page $=4 \& C F I D=34745232 \& C F T O K E N=2 e 44 c f 1767 d c 1118$-AD9CE054-ABBA-9D7987EF863FD6CD9FBF (accessed on 14 November 2014). 
5. Dincer, I.; Rosen, M.A. Thermal Energy Storage. In Systems and Applications, 2nd ed.; Wiley: London, UK, 2011; Chapter 6.

6. Coefficient of Performance. Available online: http://en.wikipedia.org/wiki/Coefficient_of_ performance (accessed on 21 July 2014).

7. Drake Landing District Heating. Available online: http://www.dlsc.ca/district.htm (accessed on 21 July 2014).

8. Tolmie, R. Concentric Ring Heat Exchangers, GeoExchange Coalition/CANSIA workshop, Toronto, ON, Canada, January 2013.

9. Data of Residential Sector-Ontario (Res: Table 4). Available online: http://oee.nrcan.gc.ca/ corporate/statistics/neud/dpa/showTable.cfm?type $=\mathrm{CP} \&$ sector $=$ com\&juris $=$ on $\& \mathrm{rn}=4 \&$ page $=4 \& \mathrm{C}$ $\mathrm{FID}=34745232 \& \mathrm{CFTOKEN}=2 \mathrm{e} 44 \mathrm{cf1} 1767 \mathrm{dc} 1118$-AD9CE054-ABBA-9D79-87EF863FD6CD9FBF (accessed on 14 November 2014).

10. Data of Residential Sector-Ontario (Res: Table 5). Available online: http:/oee.nrcan.gc.ca/ corporate/statistics $/$ neud $/$ dpa/showTable. cfm?type $=$ CP\&sector $=$ com\&juris $=$ on $\& \mathbf{r n}=5 \&$ page $=4 \& C$ $\mathrm{FID}=34745232 \& \mathrm{CFTOKEN}=2 \mathrm{e} 44 \mathrm{cf1767dc1118-AD9CE054-ABBA-9D79-87EF863FD6CD9FBF}$ (accessed on 14 November 2014).

11. Data of Residential Sector-Ontario (Res: Table 10). Available online: http://oee.nrcan.gc.ca/ corporate/statistics/neud/dpa/showTable.cfm?type $=$ CP\&sector $=$ com\&juris $=$ on $\&$ rn $=10 \&$ page $=4 \&$ $\mathrm{CFID}=34745232 \&$ CFTOKEN=2e44cf1767dc1118-AD9CE054-ABBA-9D79-

87EF863FD6CD9FBF (accessed on 14 November 2014).

12. Data of Commercial/Institutional Sector-Ontario (Com/Inst: Table 2). Available online: http:/oee.nrcan.gc.ca/corporate/statistics/neud/dpa/showTable.cfm?type=CP\&sector=com\&juris= on\&rn=2\&page $=4 \& C F I D=34745232 \& C F T O K E N=2 e 44 c f 1767 d c 1118$-AD9CE054-ABBA-9D7987EF863FD6CD9FBF (accessed on 14 November 2014).

13. Data of Commercial/Institutional Sector-Ontario (Com/Inst: Table 24). Available online: http://oee.nrcan.gc.ca/corporate/statistics/neud/dpa/showTable.cfm?type=CP\&sector=com\&juris= on\&rn=24\&page $=4 \& C F I D=34745232 \&$ CFTOKEN=2e44cf1767dc1118-AD9CE054-ABBA-9D7987EF863FD6CD9FBF (accessed on 14 November 2014).

14. Data of Commercial/Institutional Sector-Ontario (Com/Inst: Table 26). Available online: http://oee.nrcan.gc.ca/corporate/statistics/neud/dpa/showTable.cfm?type=CP\&sector=com\&juris= on\&rn=26\&page $=4 \& C F I D=34745232 \&$ CFTOKEN=2e44cf1767dc1118-AD9CE054-ABBA-9D7987EF863FD6CD9FBF (accessed on 14 November 2014).

15. Data of Residential Sector-Ontario (Res: Table 2). Available online: http://oee.nrcan.gc.ca/ corporate/statistics/neud/dpa/showTable.cfm?type $=\mathrm{CP} \&$ sector $=$ res\&juris $=$ on $\& \mathrm{rn}=2 \&$ page $=4 \& \mathrm{CF}$ $\mathrm{ID}=34781935 \& \mathrm{CFTOKEN}=\mathrm{a} 3 \mathrm{e} 4 \mathrm{~b} 094504 \mathrm{~b} 4 \mathrm{fd} 5-\mathrm{C} 1 \mathrm{ABC}$ 796-0C01-8974-3372515F5BDA14BA (accessed on 14 November 2014).

(C) 2014 by the authors; licensee MDPI, Basel, Switzerland. This article is an open access article distributed under the terms and conditions of the Creative Commons Attribution license (http://creativecommons.org/licenses/by/4.0/). 